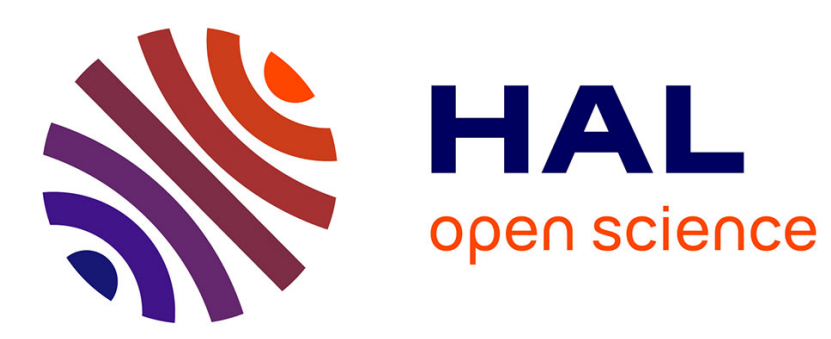

\title{
Diana Schackow: A grammar of Yakkha (Studies in Diversity Linguistics 7)
}

\author{
Aimée Lahaussois
}

\section{To cite this version:}

Aimée Lahaussois. Diana Schackow: A grammar of Yakkha (Studies in Diversity Linguistics 7). Journal of South Asian Languages and Linguistics, 2017, 10.1515/jsall-2017-0015 . hal-01657466

\section{HAL Id: hal-01657466 https://hal.science/hal-01657466}

Submitted on 6 Dec 2017

HAL is a multi-disciplinary open access archive for the deposit and dissemination of scientific research documents, whether they are published or not. The documents may come from teaching and research institutions in France or abroad, or from public or private research centers.
L'archive ouverte pluridisciplinaire HAL, est destinée au dépôt et à la diffusion de documents scientifiques de niveau recherche, publiés ou non, émanant des établissements d'enseignement et de recherche français ou étrangers, des laboratoires publics ou privés. 


\title{
Book Review
}

\author{
Diana Schackow. A grammar of Yakkha (Studies in Diversity Linguistics 7). \\ Berlin: Language Science Press, 2015, xvi, 603 pp., ISBN 978-3-946234-11- \\ 1 (Digital); 978-3-946234-12-8 (Hardcover); 978-3-946234-13-5 \\ (Softcover). €70.00 (HB)
}

Reviewed by Aimée Lahaussois, Laboratoire Histoire des Théories Linguistiques, UMR 7597 CNRS/Université Paris Diderot, Case 7034, 5 rue Thomas Mann, 75205 Paris Cedex 13 France, Email: aimee.lahaussois@linguist.univ-paris-diderot.fr

The book under review is a grammatical description of the Yakkha language, a SinoTibetan language of the Kiranti branch spoken in the Sankhuwa Sabha and Dhankuta districts of Eastern Nepal. The book is based on the author's dissertation, defended in 2014 at the University of Zurich. The author's decision to publish the book with Language Science Press (in the Studies in Diversity Linguistics series), directed by Martin Haspelmath, makes it available as a freely downloadable PDF or a print-ondemand. This ensures that readers in Nepal, among other places, will be able to benefit from this work, and both the series director and the author are to be lauded for the initiative.

The book has seventeen chapters as well as three appendices. According to the author, "[t]he grammar is written in a typological framework", but not "within any particular theoretical framework" (p. 1). Another feature of this grammar is that the author provides frequent references to cognates in other Kiranti languages, using a diachronic approach to the data whenever possible. Each chapter starts with a useful short summary of the different sections found within and their content.

The introduction (pp. 1-16) sets the context for the grammatical description, with detailed and thoughtful notes on terminological, glossing and orthographic choices. This is the type of background information which is very useful to the reader, but is unfortunately left out from many grammars. It reads as a distillation of what is interesting about the grammar, as the notes on terminology highlight topics such as nominalization (and related issues), the marking of arguments and the transitivity of verbs. Section 1.3 on data sources provides detailed metadata for the corpus, something which readers are not usually provided with, despite its relevance to developing a sense of what exactly is being described in the grammar. The introduction concludes with a very helpful typological overview of the language, including, in addition to typological features, some discussion of word class categorization.

Chapter 2 (pp. 17-39) describes the historical and sociolinguistic situation of the Yakkha language. Particularly appealing (and relevant for Kiranti scholars) is the practice of interspersing Yakkha terms (for foods, crops, objects...) in the text sections describing the material culture of the Yakkha.

Chapter 3 (pp 41-85) describes the phonemes of Yakkha: five basic vowels; voiceless plosives and affricates as well as nasals, glides, s, h, r, l (voiced consonants and retroflexes are considered marginal). The transcription adopted in examples throughout the grammar is two-tiered: an upper "phonological" line, and a lower line closer to a phonemic transcription. The grammar adopts the Nepali convention of writing $\mathrm{c}$ and ch for [ts] and [ts ${ }^{\mathrm{h}}$ ] respectively, and y for [j]. The chapter frequently provides historical and taxonomical information contextualizing the phonology of 
Yakkha within the Eastern Kiranti branch. A large section (3.5) is devoted to the morphophonological processes which operate in the language.

Chapter 4 (pp. 88-111) covers pronouns, demonstratives, quantifiers, numerals, interrogatives. The personal pronouns of Yakkha are classically Kiranti, with dual and plural number, and an exclusive/inclusive contrast on non-singular 1st persons. There is a single non-singular 3rd person personal pronoun, where some Kiranti languages maintain a dual/plural contrast. The chapter provides a list of 22 obligatorily possessed nouns (mostly kinship terms, spatial and tempoeral relations, and body parts), again interesting in that it is not the case for all Kiranti languages (Thulung, for instance, only has 'lung' as an obligatorily possessed noun).

Chapter 5 (pp 113-158) presents the noun phrase, with the introductory paragraph setting out the structural features of nouns in Yakkha alongside a characterization of the word class as it occurs in the language: "Nouns typically refer to time-stable concepts like living beings, places or things, but also to some abstract or less time-stable concepts like sakmay 'famine' or cerya 'language, matter, word'." (p 113).

This chapter provides a good example of the exhaustive character of the grammar under review: section 5.1.2 on compounding contains sections on toponyms, on botanical terms and "nouns referring to liquids", on lexical diminutives, and on rhyming in compounds. All these classes are interesting and relevant, and deserve treatment in a grammar, but the information contained therein has, as far as I know, traditionally been relegated to glossaries. This is one of the charms of the grammar: the amount of detail helps to draw a cultural picture which brings the language to life.

The category of case is well-established in Kiranti grammaticography, whether it is marked with clitics or affixes. In this description, Yakkha case markers are divided into two large categories, Group I and Group II: the former are "clitics that operate on the noun-phrase level, marking verbal arguments" (p. 125), whereas the latter are a more heterogeneous group and can occur as bound or independent forms; in the bound form, they can combine with nouns and adverbials, or function independently as adverbials. Some terms used to refer to Group II case markers are somewhat obscure (caritive, terminative, equative...) and not always used consistently (table 5.5 lists ma?nin as caritive, but the text in 5.2.3.6 uses 'privative' for the same case marker).

The description of core case marking (section 5.2.2.) reveals a somewhat surprising analysis of 'ergative/nominative' syncretism for first and second person pronouns. The situation is summed up as follows: "the differential agent marking (ergative or nominative) is mainly determined by word class (pronoun vs noun), but also by reference (speech-act participants vs. third person participants). " (p. 129) The reason the author analyses this a case of syncretism (with unmarked 1st and 2nd pronouns glossed with the likes of "1SG[ERG]", 2PL[ERG]") is that first or second person marking can sometimes be associated with a full noun instead of a pronoun, and in such cases the nouns take ergative marking, as in (1) (example (20) from p. 130):

(1) a. phu=na mamu=na yakkha cerya nis-wa-g=hon man-di-me-n=na! white=nmlz.sg girl=erg Yakkha language know-npst-2=seq be_surprised-V2.give-npst-1sg=nmlz.sg 'I am surprised since you, a white girl, know Yakkha!

It seems that this could more simply be described as a person-based ergative split, with full nouns behaving as 3rd persons even if their reference is first or second person (a different behavior for full nouns would be very surprising). This type of split occurs in other Kiranti languages (Lahaussois 2003) and to analyze the situation as syncretism can be misleading. 
Chapter 6 (pp. 159-182) presents adjectives and adverbs. There is, as in other Kiranti languages, a small number of lexical adjectives and adverbs, but they are worthy of separate treatment because of the patterns they share, which include ideophonic patterns and reduplication/triplication. An interesting feature is the limited number of basic color terms, which only include red, non-red, black and white, but are combined in such a way as to arrive at eleven color terms. Of great interest is section 6.4, which presents adjectives and adverbs that have reduplicated or triplicated syllables (although one might argue against the label 'triplication' as the pattern is $\mathrm{C}_{1} \mathrm{VC}_{2} \mathrm{VC}_{2} \mathrm{~V}$ ). These lexemes can be associated with specific semantic features (reduplicated adjectives tend to be used for physical characteristics, p. 175) or have an ideophonic component (which can also be reduplicated).

Chapter 7 (p. 183-203) presents the geomorphic orientation system of Yakkha, i.e. the encoding of spatial orientation which is absolute and not related to the speaker. This phenomenon is found in demonstratives (section 7.2), adverbs (7.3), postpositions (7.4) and in motion verbs (7.5). In the case of motion verbs, some verbs lexicalize an up/down contrast. This is, for instance, the case with the verbs of coming, which include $t a$ 'come (from a greater distance)', ke? 'come up', ap 'come (same level)', uks uך 'come down' (table 7.6).

Chapter 8 (pp. 205-268) describes the inflectional morphology of verbs, which is characterized by stem alternations and person and number indexing of subject and object through affixal (predominantly suffixal) morphology. Yakkha has the typical Kiranti monosyllabic verb template (C)V(C), which can be augmented with diachronically valence-related $-t$ or $-s$, but, unlike some languages, has no initial clusters. Verbs are grouped into two major root types, both connected with the notion of a 'stem augment', a "well established [term] in the Kiranti descriptive tradition" (footnote 1, p. 207): a) unaugmented roots for which the stem is as found in the citation form (the exception are verbs in CV? which pattern a little differently), and b) augmented roots, which include a post-final $-s$ or $-t$, manifesting in stems as, respectively, $-s$ or $-d /-r /-2$. We are reminded that these augments are unproductive, "except for $-t$, which plays a role in the benefactive derivation" (p. 210), which is a rather interesting situation and discussed in greater detail later on (p. 371).

A concise table 8.9 sums up the various root allomorphs in a very clear fashion, with pre-vocalic and pre-consonantal stem forms for all 5 types of roots (1 unaugmented type, and 4 augmented types, two in - $s$ (CV-s and CVC-s), one in - $r$ (CV-r) and one in - $t$ (CVC- $t$ or CVt, the latter coming from CVt- $t$ ).

In 8.1.2, the morphophonological behavior of stems is presented, with almost all alternations resulting from the application of phonological processes. Table 8.10 presents stem allomorphs found with a number of common verb suffixes, showing that processes such as assimilation, gliding and voicing apply. The system of stem alternations in Yakkha seems considerably simpler than comparable systems in some other Kiranti languages (see for example Jacques et al 2012 on Khaling verbal morphology).

As far as person, number and syntactic role marking are concerned (section 8.2), "from a comparative Kiranti perspective [...] the Yakkha verbal inflection looks fairly simple and regular" (p. 216, footnote 11). The verbal template involves 1 prefixal (for negation or 3PL S or A) and 11 suffixal slots, with slots being allotted for nasal copying as well (p. 219). As mentioned by the author, the single prefixal slot makes Yakkha look more like Western Kiranti languages than its surrounding languages. 
The tables laying out inflectional morphology are typical of Kiranti paradigms (presented since Allen 1975 with agent in the vertical axis and patient in the horizontal). Because of the transparency of stem alternations, distinct tables are not needed for every combination of root $\mathrm{V}$ and final consonant (+ augment), and just a few tables suffice to exemplify the entire system, resulting in a much lighter presentation than what is needed for some other languages, such as Khaling (see Jacques et al, 2012). Figure 8.2 offers an elegant representation of the slots in the paradigm which share the same person/number markers. This is something that has traditionally been presented in text format in grammars of the Leiden school (see van Driem 1987: p. 77-89), but the visual representation is very effective for highlighting patterns.

Section 8.3 presents polarity, with two sets of negation markers: one for nonfinite forms and another for finite inflected forms. Section 8.4 describes the overt marking of tense and aspect, with two distinct non-past markers, - $m e$ ? and - $w a$, both of which are historically function verbs which were grammaticalized (their distribution is exemplified in Table 8.14). Yakkha has three past tenses: simple past, perfect and past perfect. Moods, described in 8.5, include indicative, subjunctive, optative and imperative. Interestingly, the non-past subjunctive is unmarked in Yakkha (the past subjunctive is mostly marked like indicative past), and the examples given in (40) are all situations that would be expressed as indicative (which is the unmarked mood) in Western Kiranti languages. Section 8.7 presents the two copulas, an identificational copula and an existential copula wama, and their inflectional paradigms.

Chapter 9 (pp. 269-288) presents noun-verb predicates. These are fixed collocations in which a noun is associated with a verb to form a predicate (eg. nam phemma 'shine [sun]'). According to the author, they should be distinguished from noun incorporation because they show "different degrees of morphological fusion" (p. 272). Indeed, in some cases the noun can be topicalized, or coordinated with another nounverb predicate sharing the same light verb (the two nouns can be coordinated through a comitative marker), thus showing that the noun has a certain degree of autonomy within the construction, while in other cases, the noun is not attested independently of the compound. They are divided in this chapter into 'simple noun-verb predicates' (9.1) and 'experiencer-as-possessor' constructions. (9.2). The latter type, the most prevalent way of expressing experiential events in Yakkha, receives detailed description in this chapter.

Chapter 10 (pp. 289-328) deals with complex predication, i.e. predicates that consist of more than one verbal stem, common in Kiranti languages. The semantics and syntax of the grammaticalized and/or lexicalized constituents of such complex predications, called 'second verbs', or V2's, are discussed in the chapter for each individual V2. The author explicitly glosses verbs that are used as V2's with their source lexical meaning in SmallCaps, in the format V2.SourceVERB, as in (2) (example (1b) from p. 289):

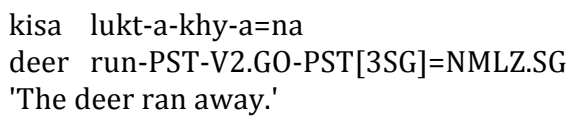

In cases where the lexical source V2 cannot be determined, it receives a semantic gloss, such as COMPL for the completive -i (p.302), in order to avoid complicated semantic labels that fail to cover all uses of the V2 in question. Semantic shifts attested for some V2 verbs are fairly unusual and typologically rare, as is the case with the verb $c a$ 'eat' marking reflexive, middle, and autobenefactive when employed as V2.EAT. The same V2 is also found in lexicalized compounds with idiomatic semantic shifts such as yuncama 
'laugh, smile' (<yut, 'sharpen'), suncama 'itch' (<sus, 'get sour'), incama 'play' (<is 'rotate, revolve') (summarized in table 10.3). The situation with the sources of some V2's is even more complicated, as is the case with the continuative V2 -nuך, tentatively connected to yun 'sit'. In spite of complexity of the material, its presentation is, in general, very clear. For some V2's with telic or completive reading, such as completive quasi-V2 -i -ni (10.2.2), telic V2 -khe? (10.2.5), irreversible V2 -haks (10.2.16), quasi-V2 -a -na 'do X and leave object' (10.2.18) additional examples for non-past uses would be helpful, because in some cases the interpretations seem to heavily depend on tense.

Chapter 11 (pp. 329-383) discusses argument realization (11.1), valency alternations and labile verbs (11.2), and transitivity/valency changing operations (11.3). The latter includes passivization and antipassivization, benefactive, reflexive and middle constructions (all using V2's discussed in chapter 10), and a reciprocal construction. The last section of the chapter (11.3.8) offers a discussion of the Yakkha verbs which provide evidence of Proto-Tibeto-Burman transitivizing suffixes $-s$ (causative) and $-t$ (directive).

Chapter 12 (pp. 385-398) gives an overview of the different types of simple clauses found in Yakkha, while chapter 13 (pp. 399-425) deals with nominalization and relativization. Yakkha fits into the Standard Sino-Tibetan Nominalization pattern (Bickel 1999, among others). The distribution of nominalizers is as follows: -khuba (sometimes -khuma) for A/S roles, and -na/-ha for any other role (singular and non-singular respectively). The latter are "almost unrestricted with respect to grammatical relations" (p.407), that is, can be used to change a verb to a noun corresponding to nearly any grammatical relation. Examples provided by the author illustrate relativization upon the roles of S, P, G (most goal-like argument), T (other most patient-like argument after $\mathrm{P}$ ), location and comitative; all examples are from narratives. Examples of other roles as targets of relativization would be in order; in particular, it is unclear if ablative or allative (unmarked case in Yakkha) relative clauses are possible in Yakkha. It would also be interesting to see how relativization operates with verbs incorporating directions (see chapter 7).

Chapter 13 also discusses some issues of complementation (treated at length in chapter 15) and sentential nominalizations. The author shows that these nominalizations are pragmatically marked in Yakkha and other Kiranti languages, claiming that "main clauses are nominalized to set them apart from the surrounding discourse" (p. 416). Such claims are very difficult to evaluate without access to the entire narrative which the examples are taken from ; it would be useful to refer to an online text archive that could support this conclusion.

Chapter 14 (427-462) describes adverbial clause linkage, which does not involve complement clauses or relative clauses. There are a number of types, varying in the finiteness of the adverbial clause in question (converbal, infinitival, or finite) and in semantics, summarized in table 14.2. Like in other Kiranti languages, the morphology of clause linkage may involve case markers.

Chapter 15 (pp. 463-498) focuses on complementation. The author distinguishes between infinitival complement clauses (15.1) and inflected complement clauses (15.2), discussed in terms of the complement clause semantics outlined by M. Noonan 1985. All types of complement are conveniently summarized in table 15.1), which shows that the main distinction between the two types of clauses is that inflected complements are found exclusively with utterance predicates such as kama, 'say', lu?ma 'tell', chimma 'ask', yokme?ma 'tell about something' (15.2.2) and can also be used with verbs of 
cognition and experience (15.2.1), while infinitival complements are found with all other types of complement-taking predicates.

Chapter 16 (pp. 499-502), "Connectives on the text level" presents words that serve to connect clauses in a sequential, simultaneous, adversative or causal relationship (connectives).

Chapter 17 (pp. 503-527) deals with discourse particles and interjections, which are rarely discussed in grammars of languages of Nepal (exceptions are Toba 1984 and Watters 2002, where interjections are treated in a special chapter/section), obviously due to the marginal character of interjections in morphosyntax. The author herself describes the main content of the chapter as "a descriptive overview" (rather than a theoretical analysis) of discourse particles. These include, among others, the irrealis particle (p. 518), found with counterfactuals and hypothetical clauses (although, in my view, this particle belongs to verb morphology rather than operates at the clause level).

The book concludes with three appendices: three narrative texts, kinship diagrams, and an index of formatives (along with their functions and references to the relevant sections of the book).

The book under review is an exhaustive grammatical description of Yakkha, both as to the material covered and its linguistic analysis and discussion. The grammar also includes discussion and textual examples of some word classes which are often relegated to the lexicon, such as interrogatives and interrogative proforms or cardinal numbers (of which only '1', '2' and '3' are still used.) The book is also provided with ample bibliography on Kiranti languages and cultures as well as theoretical issues that are relevant for various aspects of morphosyntax discussed in the individual chapters. Glossing is very transparent and consistent Leipzig with Leipzig glossing rules.

Overall, this grammar is a welcome addition to the current body of work on Kiranti languages, setting a very high standard for future research on this subgroup.

\section{References}

Allen, Nicholas J. 1975. Sketch of Thulung grammar (Cornell University East Asia Papers 6). Ithaca, NY: Cornell University.

Bickel, Balthasar. 1999. Nominalization and focus constructions in some Kiranti languages. In Yogendra P. Yadava and Warren G. Glover (eds.), Topics in Nepalese linguistics, 271-296. Kathmandu: Royal Nepal Academy.

Jacques, Guillaume, Aimée Lahaussois, Boyd Michailovsky \& Dhan Bahadur Rai. 2012. An overview of Khaling verbal morphology. Language and Linguistics 13(6). 1095-1170.

Lahaussois, Aimée. 2003. Ergativity in Thulung Rai: a shift in the position of pronominal split. In David Bradley, Randy LaPolla, Boyd Michailovsky \& Graham Thurgood (eds.), Language Variation: Papers on variation and change in the Sinosphere and in the Indosphere in honour of James A. Matisoff, 101-112. Canberra, Australian National University (Pacific Linguistics).

Noonan, Michael. 1985. Complementation. In Timothy Shopen (ed.) Language Typology and Syntactic Description. 42-140. Cambridge: Cambridge University Press.

Toba, Sueyoshi. 1984. Khaling, 2nd edn. Tokyo: ILCAA, Tokyo University of Foreign Studies.

van Driem, George. 1987. A grammar of Limbu. (Mouton Grammar Library, 4) Berlin, New York and Amsterdam: Mouton de Gruyter

Watters, David E. 2002. A grammar of Kham. Cambridge: Cambridge University Press. 